\title{
¿Qué nos enseñan \\ las escuelas sobre la educación de los niños pobres en Chile? \\ educt
}

\author{
Beverley A. Carlson \\ Oficial de Asuntos Sociales, \\ División de Desarrollo \\ Productivo y Empresarial, \\ CEPAL \\ bcarlson@eclac.cl
}

La reforma educativa ha sido una de las tareas más importantes de América Latina a partir de los años noventa. Los países latinoamericanos, en los que la educación en las escuelas públicas a menudo ha sido deficiente, necesitan ampliar las oportunidades de educación y mejorar la calidad de la enseñanza. No basta con estudiar las políticas de educación a nivel macro que articulan los gobiernos y ejecutan centralizadamente los ministerios de educación: la teoría suele diferir mucho de lo que sucede a nivel micro en las escuelas cuando se aplican las políticas educativas. Las políticas y la realidad social convergen en las aulas, y las escuelas nos pueden enseñar mucho sobre cómo lograr una educación básica de calidad. Este artículo se centra en los niños pobres de las escuelas pobres y los desafíos permanentes que plantea la educación en las comunidades pobres. El programa chileno dirigido a mejorar la calidad de la educación y sus resultados en 900 de las escuelas básicas pobres del país, conocido como P900, proporcionó un marco ideal para identificar y estudiar los problemas que enfrentan las escuelas de comunidades pobres y comprender cómo y por qué tienen dificultades para alcanzar los estándares nacionales. A través de este estudio se intenta aprender de las escuelas y comprender mejor las dificultades prácticas que les plantea la educación de los niños pobres, en el contexto de la comunidad a la que pertenecen y la población de alumnos a la que sirven. En el plano nacional, se utilizó una metodología de investigación a nivel macro para identificar las escuelas de menor rendimiento del P900, comparando los resultados de las escuelas en pruebas estandarizadas y las tendencias de esos resultados durante el decenio de 1990. De este grupo se extrajo una pequeña muestra intencionada de las escuelas con resultados menos satisfactorios, utilizando técnicas de muestreo por cuotas que reflejaran las principales características del conjunto de escuelas incluidas, y se realizaron estudios de cada una de las escuelas seleccionadas, mediante visitas y entrevistas que tenían por objeto conocer a fondo su desempeño y el de sus alumnos, e individualizar los factores críticos que pudiera ser necesario modificar. Para cada escuela se elaboraron informes exhaustivos. El presente artículo reseña las lecciones extraídas de estos estudios a nivel micro. 


\section{Evaluación de la calidad de la educación: del nivel macro al nivel micro}

La reforma educativa ha sido una de las tareas más importantes emprendidas en América Latina en los años noventa. ${ }^{1}$ En Chile, se ha dado prioridad en la reforma al mejoramiento de la calidad y de la equidad de la educación en el sector público. ${ }^{2}$ Este país está tratando de mejorar la educación a través de la aplicación de medidas en cuatro esferas principales: la reforma curricular; el fortalecimiento de los programas de formación de profesores en las universidades; la ampliación de la jornada escolar en la educación básica ${ }^{3}$ de turnos de mediodía a jornada completa, y el mejoramiento de la calidad. Estas iniciativas comenzaron a aplicarse a principios de los años noventa, pero como se trata de una empresa de gran magnitud los resultados de las reformas, en la medida en que éstas tengan éxito, sólo se verán en el largo plazo.

La reforma educativa y las políticas nacionales de educación no se traducen automáticamente en una mejor educación en las escuelas. Son un punto de partida importante, el marco macro, jurídico y financiero. La transformación de las reformas en políticas y programas, su ejecución y la adopción de medidas que afectan a los alumnos de las escuelas constituyen un

\footnotetext{
$\square$ En el presente artículo se sintetizan y amplían las conclusiones de un estudio a nivel macro y micro titulado Achieving educational quality: What schools teach us publicado por la CEPAL en enero de 2000 (próximamente se publicará en español). La autora desearía expresar su gratitud al Ministerio de Educación de Chile y al Programa P900, a las autoridades provinciales y municipales y, especialmente, a cada una de las escuelas incluidas en el presente estudio, que compartieron su tiempo, su esfuerzo y sus conocimientos y son el núcleo de este trabajo. Asimismo, desea agradecer a Jorge Katz por sus valiosas observaciones sobre el borrador de este artículo; a Joe Ramos por sus consejos sobre el diseño del proyecto y sus observaciones sobre una versión anterior; a Pilar Bascuñán, Elizabeth Love y Howard La Franchi por su asesoramiento técnico y su ayuda para las entrevistas en las escuelas y la preparación de los informes; y a los directores, docentes, niños y padres que dieron su tiempo y su visión sobre las dificultades permanentes que plantea la educación de los niños de las comunidades pobres.

1 Véanse Gajardo (2000); Banco Mundial (1999); PREAL (1998) y Rojas y Esquivel (1998).

2 Véanse García-Huidobro (1999); García-Huidobro y Jara (1994); Schiefelbein y Schiefelbein (1999); Cox (1997), y Carnoy y McEwan (1997).

${ }^{3}$ En Chile la educación básica —o primaria - obligatoria abarca
} ocho años de estudio. desafío enorme en el que intervienen muchos factores y protagonistas. Las reformas son declaraciones de intención. En consecuencia, evaluar las reformas declaradas no es suficiente. Para buscar los resultados hay que ir a las escuelas y examinar el desempeño individual de los alumnos, es decir, ubicarse en una perspectiva micro.

El presente artículo se centra en los niños pobres de las escuelas pobres, el desafío permanente de educar a los niños de las comunidades pobres y lo que esto nos puede enseñar con respecto al logro de una educación básica de calidad. ${ }^{4}$ Como la escuela está en la base de la pirámide burocrática constituida por todos los que participan en la actividad educativa, primero es preciso comprender la estructura de la educación básica en Chile y los motivos por los cuales es tan peculiar. El sistema de educación chileno es un sistema mixto público-privado. Existen tres tipos de escuelas básicas: las municipales, que reciben subvención del gobierno central y son administradas por los municipios; las escuelas privadas que también reciben subvención del gobierno central pero se administran en forma privada, y las escuelas privadas cuyo financiamiento y administración son privados. Este arreglo tripartito es el legado de la reforma escolar de principios de los años ochenta, mediante la cual la administración de las escuelas se transfirió de las autoridades del gobierno central a los municipios o a entes privados. También es el resultado de una política oficial cuyo objeto era proporcionar incentivos al sector privado para que aportara medios educativos e introdujera la competencia en el sistema. En realidad, sólo el $8 \%$ de las escuelas básicas son totalmente privadas, es decir, pertenecen a la tercera categoría; pero más de la cuarta parte pertenece a la categoría mixta de escuelas privadas que reciben subsidios del gobierno central; los dos tercios restantes son municipales.

Las políticas de educación y la realidad social convergen en las aulas de las escuelas de todo el país. $\mathrm{Al}$ evaluar la calidad de la educación, no es razonable

\footnotetext{
${ }^{4}$ Véase Carlson (2000).
} 
ni justo comparar el desempeño de los alumnos y de las escuelas sólo sobre la base de los resultados de pruebas estandarizadas. Los alumnos que ingresan a las escuelas poseen "calidades" diferenciales, resultantes de una amplia diversidad de factores. Estos abarcan desde su desarrollo cerebral -en el que influye fuertemente la atención y la alimentación recibida en sus primeros años de vida - hasta el vivir en un hogar que promueva el aprendizaje y la interacción social. Los factores mencionados limitan lo que las escuelas pueden lograr por sí mismas en términos estrictamente cuantitativos, especialmente cuando están ubicadas en vecindarios más pobres, social y económicamente desfavorecidos, donde enfrentan problemas mucho más graves que las escuelas ubicadas en vecindarios más ricos.

La calidad de la educación no puede evaluarse sólo teniendo en cuenta cuáles son los alumnos y las escuelas que logran los puntajes más altos en las pruebas estandarizadas, ya que los tipos de estudiante que concurren a las diferentes escuelas son muy distintos. En una situación ideal, nos gustaría poder evaluar individualmente la evolución del desempeño de los alumnos a medida que avanzan en la escuela básica y media. En la mayoría de los casos esto no es posible. Cuando más, algunos países realizan pruebas nacionales e internacionales de logros educativos - a menudo en $4^{\circ}$ y $8^{\circ}$ grados-, lo que les permite efectuar una evaluación transversal del desempeño de los alumnos de esos grados en el año en que se toma la prueba. Los resultados, agregados a nivel de escuela, permiten obtener una imagen instantánea de los alumnos de $4^{\circ}$ y $8^{\circ}$ grados de cada una de las instituciones.

Esto es lo que ocurre en Chile con el Sistema de Medición de la Calidad de Educación (SIMCE). Es muy fácil acceder a los resultados anuales del SIMCE. Estos incluso se publican en los periódicos nacionales y se alienta a los padres y alumnos a que los consulten. A tales estadísticas se les da usos muy diversos, no siempre adecuados. ${ }^{5}$ Ricardo Lagos, ex Ministro de Edu-

\footnotetext{
${ }^{5}$ Para utilizar adecuadamente los resultados de las pruebas del SIMCE de $4^{\circ}$ grado es preciso tener en cuenta las mediciones conocidas y los problemas de interpretación, que han sido examinados por varios investigadores (véase Martínez, 1996, Espínola, 1996; y Olivares, 1996) y que pueden producir un sesgo hacia arriba, incrementando los puntajes artificialmente, sobre todo en las escuelas más pequeñas o de baja calidad educativa. Las estadísticas publicadas sobre las tendencias en el desempeño promedio, clasificadas por tipo de escuelas - por ejemplo, municipales, privadas subvencionadas o escuelas adscritas al Programa P900 - se ven distorsionadas por varios factores, que comprenden la continuidad de los instrumentos de verifica-
}

cación y actual Presidente, ha dicho que el resultado de las pruebas del SIMCE era el único método objetivo de evaluar el desempeño escolar en el plano nacional con el objeto de brindar asistencia especial a las escuelas más pobres y más necesitadas (véase Undurraga, 1998). Por otra parte, las escuelas que han obtenido buenos resultados en las pruebas del SIMCE suelen utilizarlos para atraer más estudiantes, especialmente las escuelas privadas que reciben subvenciones públicas. Este hecho es importante porque el monto de la gran mayoría de tales subsidios depende del número de alumnos matriculados. Los padres también consultan los resultados anuales publicados en los periódicos locales para determinar cuáles son las mejores escuelas para sus hijos.

La opinión de muchos administradores escolares y docentes es otra. Consideran que el SIMCE mide de manera injusta su propio desempeño y el de los alumnos, especialmente en los vecindarios más pobres. Piensan que en este sistema no se tienen en cuenta las diferentes capacidades de su alumnado, la disparidad de recursos con que cuentan las escuelas o el nivel de interés y participación de los padres. Todos estos puntos de vista tienen importancia.

En resumen, los datos sobre los resultados obtenidos por los alumnos son una medida útil de desempeño a condición de que se utilicen adecuadamente. Sin embargo, sólo nos brindan información sobre el resultado final, el "qué". Pero mucho más importante que éste es el "por qué". Para entender los resultados del aprendizaje es esencial comprender lo que ocurre en las escuelas, centro de aprendizaje de las personas durante al menos 12 años de su vida. Sabemos que los factores extraescolares son sumamente importantes, sobre todo en los vecindarios y las familias pobres, pero la escuela sigue siendo el primer peldaño de responsabilidad institucional en el aprendizaje de los educandos. Por tal motivo es fundamental "bajar hasta la escuela" y examinar la realidad escolar, habida cuenta de la diversidad de factores que componen esa realidad.

ción, los efectos producidos por la participación de muchas nuevas escuelas en las pruebas (Mizala y Romaguera, 1998), así como también por el eterno problema del método de calificación utilizado. Otros autores (Eyzaguirre y Fontaine, 1999) manifiestan su preocupación por el bajo nivel de dificultad de las pruebas del SIMCE de $8^{\circ}$ grado - equivalente a dos o tres grados menos- porque puede ser un factor limitante para mejorar la calidad educativa. Además consideran que la característica mencionada refleja una falta de continuidad entre las exigencias de la educación básica y la de la educación media. Aunque estos problemas van más allá del objetivo del presente estudio, se les ha tenido en cuenta. 


\section{II}

\section{Los resultados de la educación}

\section{en las escuelas pobres}

Las autoridades de educación chilenas brindaron una oportunidad para examinar los logros educativos vinculados con el programa nacional dirigido a mejorar la calidad del desempeño educativo en 900 de las escuelas básicas pobres de Chile, conocido como el Programa P900. ${ }^{6}$ Les interesaba recibir asistencia para entender por qué el desempeño de algunas escuelas no mejoraba a pesar de los insumos especiales y la asistencia de este Programa - suministrados durante varios años - a fin de poder adoptar las medidas correctivas necesarias. Inicialmente, la CEPAL había propuesto exactamente lo contrario, es decir, examinar por qué algunas escuelas tenían resultados sobresalientes pese a las dificultades comunes, y difundir las "lecciones aprendidas". En uno y otro caso se plantean problemas similares, ya sea que se trate de determinar por qué algunas escuelas y alumnos tienen un desempeño sobresaliente o por qué algunas escuelas y alumnos no cumplen con las expectativas. En ambos es necesario combinar una evaluación de los resultados cuantitativos con una investigación cualitativa que permita explicarlos.

Se decidió centrar la atención en las escuelas, en su carácter de centro de enseñanza y de adopción de decisiones, y estudiar de cerca lo que ocurre en ellas. Es allí donde se aplican y ponen a prueba las políticas y programas educativos, teniendo como marco todos los factores que inciden en la calidad de la educación. La escuela es la "primera línea de fuego", en la que las autoridades escolares deben abordar por primera vez la situación de los niños y su nivel de preparación para el aprendizaje. Es el lugar en que lo intangible se convierte en tangible. Por lo tanto, el aspecto más importante de este estudio está constituido por los conocimientos obtenidos en los establecimientos escolares, ya que en éstos se confrontan las políticas y la práctica.

La investigación se realizó en 1998 durante el año escolar, que en Chile va de marzo a diciembre. Se propuso una metodología de doble acción que, en tér-

\footnotetext{
${ }^{6}$ Véanse diversos documentos sobre el P900 y el simce publicados
} por el Ministerio de Educación. Véase también Angell (1996). minos generales, entraña la aplicación de métodos cuantitativos y cualitativos. Era fundamental utilizar métodos estadísticos no sesgados para individualizar a las denominadas "peores escuelas" del Programa P900 y rastrear su desempeño en el tiempo medido por los resultados de las pruebas del SIMCE a partir de 1990, fecha en que se puso en marcha el Programa. Más de 2100 escuelas básicas municipales y privadas subvencionadas habían participado en el P900 durante uno o más años. De este gran número de escuelas, se individualizó un núcleo de 308 que habían permanecido en el P900 durante cinco años o más y que aún no habían egresado de él. De este grupo se seleccionaron las 100 escuelas que en ese momento tenían el desempeño más bajo y de este último se extrajo una pequeña muestra intencionada de escuelas de desempeño deficiente, utilizando técnicas de muestreo por cuotas que reflejaran las principales características del grupo en los aspectos que más interesaban: escuelas urbanas o rurales; pequeñas, medianas o grandes; más pobres o más ricas; ubicadas en diversas regiones geográficas; municipales o privadas con subvención oficial (véase la sección III).

En el estudio se utilizaron los puntajes de las pruebas del SIMCE de $4^{\circ}$ grado correspondientes al período 1990-1996, con un seguimiento de los resultados de las pruebas del SIMCE de $8^{\circ}$ grado hasta 1997. En 1996 se comenzaron a aplicar cambios en el currículo para los grados $1^{\circ}$ a $4^{\circ}$, y algunos años después también se modificaron aquellos de los grados $5^{\circ}$ a $8^{\circ}$. La metodología se modificó en consecuencia. Por lo tanto, los resultados de las pruebas del SIMCE para el período 1990-1996 correspondieron a la última cohorte "comparable" para $4^{\circ}$ grado, y los resultados del período 1991-1997 fueron los últimos comparables para $8^{\circ}$ grado. La disponibilidad de resultados comparables durante tantos años permitió rastrear el desempeño e investigar los motivos de los cambios o de la falta de progreso observado durante un período largo. En el gráfico 1 se muestran los puntajes promedios de las pruebas del SIMCE en matemáticas y castellano para el $4^{\circ}$ grado durante el período 1990-1996. Estos datos ilustran los patrones de desempeño de distintos tipos de escuelas. 
GRAFICO 1
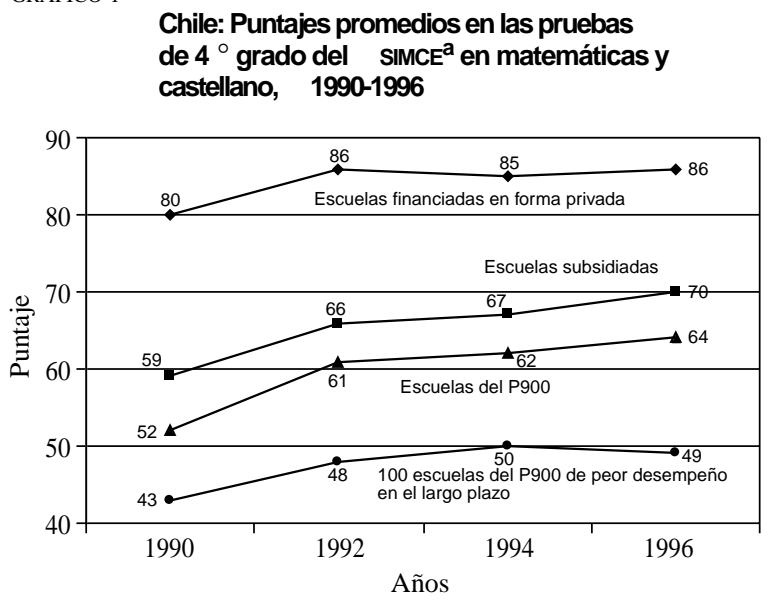

a SIMCE $=$ Sistema de Medición de la Calidad de la Educación.

El puntaje máximo teórico en las pruebas de desempeño del SIMCE es 100. Durante el período que abarca el estudio, el puntaje promedio en las pruebas del SIMCE de los estudiantes de $4^{\circ}$ grado en las escuelas subsidiadas, ${ }^{7}$ tanto municipales como privadas, aumentó 11 puntos, alcanzando un máximo de 70 en 1996. En las escuelas del P900 se observó un incremento similar de 12 puntos. Esto parece indicar un mejoramiento generalizado del desempeño educativo, siempre y cuando se hayan mantenido constantes las normas de evaluación de las pruebas. No es posible determinar en qué medida el aumento de los puntajes de las escuelas del P900 se debe a avances de las escuelas incluidas, o a la incorporación al Programa de otras escuelas que desde un principio tenían un mejor desempeño en las pruebas del SIMCE. En ambos grupos se observó que entre 1990 y 1992 hubo un progreso apreciable, mucho mayor que en cualquiera de los intervalos subsiguientes.

El desempeño en las pruebas del SIMCE de las escuelas privadas no subsidiadas demuestra que existe una disparidad muy grande entre los logros educativos y oportunidades de la elite constituida por el $8 \%$ de alumnos cuyas familias pueden pagar tales escuelas y los de los alumnos de clase media y baja que asisten a escuelas subsidiadas por el Estado. Los ni-

\footnotetext{
7 Algo menos del $70 \%$ de las escuelas subsidiadas realizaron la prueba del SIMCE en 1996 debido a la existencia de reglas de exclusión y descalificación. Asimismo, algunas escuelas optaron por no rendir la prueba. Las que con mayor probabilidad no hayan participado son las escuelas pequeñas y remotas. Sin embargo, para poder solicitar la incorporación al Programa P900 se exige a las escuelas rendir dicha prueba.
}

ños que estudian en las escuelas de elite lograron un puntaje máximo de 86 en las pruebas del SIMCE en 1996, es decir, casi el doble del puntaje de las 100 escuelas del P900 de peor desempeño en un período prolongado, que son el objeto de este estudio.

Anualmente participan en el P900 unas 900 escuelas; entre 1990 y 1996 tomaron parte más de 2100. En 1996 permanecían en el Programa 308 escuelas de bajo desempeño que no habían podido egresar de él, pese a que habían recibido la asistencia correspondiente durante cinco o más años. Los puntajes en la prueba del SIMCE de las 100 escuelas de peor desempeño de este grupo, con larga participación en el P900 —es decir, el tercio inferior - se indican también en el gráfico 1 . Tras un incremento inicial relativamente pequeño en 1992, estas escuelas se estancaron entre 1994 y 1996 e incluso mostraron una ligera declinación. De ellas se ocupa el presente estudio.

Debería recordarse, sin embargo, que ellas no son necesariamente las "más pobres de las pobres", y tal vez ni siquiera muy pobres, como se refleja en el índice de vulnerabilidad de cada escuela visitada, que veremos más adelante en el cuadro 1. El índice aplicado es el que utiliza la Junta Nacional de Auxilio Escolar y Becas (JunAeb) y por el cual se determinan los programas de alimentación de las escuelas y se envía mayor cantidad de alimentos a las más necesitadas. Los valores del índice van de 1 a 5 , siendo 1 el mínimo de vulnerabilidad y 5 el máximo. El índice de las escuelas visitadas oscila entre 2 y 5 , es decir, ellas incluyen a niños de vulnerabilidad baja, mediana y alta. Esto se debe a que el P900 procura lograr cierto equilibrio regional, mientras que las escuelas pobres tienden a concentrarse en determinadas regiones. Es mucho más probable que las escuelas más pobres estén entre las 2500 escuelas básicas excluidas o descalificadas de las pruebas del SIMCE, en su gran mayoría escuelas rurales pobres, a menudo pequeñas y de difícil acceso. La asistencia educativa que pueden recibir estas escuelas generalmente forma parte del Programa de Mejoramiento de la Calidad y Equidad de la educación (MECE) dirigido a las escuelas rurales pobres más pequeñas.

$\mathrm{Al}$ extraer conclusiones de este estudio debería tenerse presente que más de la tercera parte de las escuelas subsidiadas no está mejor, sino probablemente peor, que las escuelas estudiadas aquí. Ciertamente, muchas "lecciones aprendidas" en las visitas a los establecimientos escolares serán pertinentes para una proporción significativa de las escuelas básicas subsidiadas del país, sean éstas municipales o privadas, y tendrán suma importancia en el mejoramiento de la calidad y la equidad de la educación básica. 


\section{III}

\section{Metodología de investigación a nivel micro}

En el presente estudio se sintetizan las comprobaciones realizadas a nivel micro en las visitas a las escuelas y se extraen conclusiones sobre los problemas de calidad de la educación a nivel macro. Esencialmente, las comprobaciones macro-micro diferencian entre lo macro (el qué) y lo micro (el cómo). En el nivel macro los elementos orientadores son los indicadores de desempeño, las estadísticas, las políticas, los programas y el financiamiento. En el nivel micro, las escuelas nos dicen "cómo se ejecuta qué" en la práctica y en el contexto del grupo beneficiario, es decir, la población de alumnos a la que prestan servicios las escuelas.

Los métodos cualitativos consistieron en la realización de visitas de un día a cada una de las escuelas de la muestra. Estas visitas las efectuaba la directora del proyecto acompañada por un periodista. Se llevaron a cabo entrevistas exhaustivas con los actores principales: alumnos, docentes, directores, apoderados, personal administrativo de las escuelas y autoridades educacionales provinciales y municipales. El grupo de interés principal estaba constituido por los niños de $4^{\circ}$ grado, ya que durante el período que abarca el estudio el Programa P900 estaba dirigido a los niños del primer ciclo, es decir, los primeros cuatro grados. Además, como las pruebas del SIMCE se aplicaban cada dos años a los alumnos de $4^{\circ}$ grado, eran un indicador conveniente del desempeño de los alumnos de este nivel e, indirectamente, del desempeño y efecto del Programa en el ámbito de las escuelas.

El desempeño escolar en el $8^{\circ}$ grado también resultó útil para evaluar el logro de las escuelas en el segundo ciclo $-5^{\circ}$ a $8^{\circ}$ grado- y para determinar si se mantenían los efectos de los insumos iniciales del P900 a medida que los estudiantes avanzaban en el sistema.

Para realizar correctamente la investigación a nivel micro fue preciso dedicarle mucho tiempo y planificarla cuidadosamente con el fin de obtener de la escuela una retroalimentación no sesgada, verídica y espontánea. En lo posible, la directora del proyecto debía visitar cada escuela para asegurar la coherencia $\mathrm{y}$ aprovechar las experiencias adquiridas en las entrevistas anteriores. Estas debían llevarse a cabo en forma privada, sin la presencia de funcionarios del Ministerio de Educación o de funcionarios locales o provin- ciales, con el fin de crear las condiciones óptimas para que los entrevistados pudieran expresar sus opiniones con franqueza. Si bien para las entrevistas se contaba con un guión, puesto que las preguntas se elaboraban antes de la visita a la escuela y se adaptaban a cada tipo de entrevista (director de escuela, director técnico, docentes de $4^{\circ}$ grado, todos los docentes, alumnos, padres, y funcionarios provinciales y municipales), esas preguntas se formulaban con flexibilidad y se complementaban conforme a la evolución de las entrevistas. Si la información obtenida difiriera de la disponible en el plano nacional, la causa sería la diversidad de percepciones y conocimientos de los funcionarios locales y de los establecimientos escolares.

Las escuelas fueron seleccionadas según los criterios siguientes:

- Al momento de la investigación, debían estar participando en el P900.

- Tenían que haber estado participando en el Programa por cinco años o más y no haber egresado de él.

- El puntaje medio de $4^{\circ}$ grado en matemáticas y castellano obtenido en la prueba del SIMCE en 1996, último año en que se había tomado la prueba, debía ser igual o inferior a 60 .

- La evolución de los puntajes medios en matemáticas y castellano obtenidos en la prueba del SIMCE para $4^{\circ}$ grado debía ubicarlas en el grupo de escuelas del P900 con bajo desempeño crónico. Así, los puntajes debían registrar un deterioro ininterrumpido o periódico o una falta evidente de progresos, en contraposición con los avances continuos observados en los puntajes equivalentes de las escuelas del P900 en su conjunto.

- Sólo se podía seleccionar una escuela por región.

- Una o dos de las escuelas seleccionadas debían ser escuelas privadas subvencionadas y no escuelas municipales, puesto que aproximadamente el $25 \%$ de las escuelas del P900 pertenecen a la primera categoría.

- La mitad de las escuelas seleccionadas debían estar ubicadas en zonas urbanas y la otra mitad en zonas rurales, reflejando el hecho de que el $46 \%$ de las escuelas del P900 son urbanas y el $54 \%$ rurales. 
- La muestra de escuelas seleccionadas debía reflejar la amplia diversidad de la matrícula.

- Asimismo, las escuelas incluidas debían representar toda la gama de años de participación prolongada en el P900 —entre cinco y ocho años.

- El promedio del puntaje en matemáticas y castellano en la prueba del SIMCE para $4^{\circ}$ grado varía considerablemente de una región a otra. Como uno de los criterios de inclusión de una escuela en el sistema P900 es la relación entre el puntaje obtenido por ella en el SIMCE y el puntaje medio regional, las escuelas seleccionadas debían reflejar la gama regional de esos puntajes.

- Debía estar representada la mayor cantidad posible de los cinco quintiles de la proporción de niños vulnerables por comuna, conforme a la evaluación realizada mediante el índice de vulnerabilidad utilizado por la JUNAEB.

Estos criterios ${ }^{8}$ se clasificaron y analizaron cuidadosamente para cerca de 900 escuelas incluidas en el P900 en el momento del estudio. Entre ellas se identificaron las 100 escuelas con los puntajes más bajos en las pruebas del SIMCE y se elaboró una lista de preselección estratificada de 24 escuelas. Lo que se buscaba era sondear lo más profundamente posible en cada escuela, examinando todos los factores y consultando a cada uno de los actores. Para lograr esa profundidad y por motivos de recursos, tiempo y plazos de presentación, se decidió visitar seis escuelas en vez de las 24 seleccionadas, ya que esto hubiera generado demasiados estudios de casos y no hubiera permitido prestar atención suficiente a cada escuela. En consecuencia, se seleccionaron seis de las 24 , realizando un muestreo por cuotas en lugar de utilizar técnicas de muestreo aleatorio, a fin de reflejar las características más importantes de este grupo de escuelas en el mayor número posible de dimensiones de cada una de las variables. En el cuadro 1, que resume las características de las escuelas, se observa que ellas cumplían con los criterios establecidos y abarcaban casi todas las dimensiones de las variables claves. Además, se visi-

\footnotetext{
${ }^{8}$ Habría que haber tenido en cuenta varios otros factores cuya importancia es obvia, pero resultó imposible hacerlo ya que no se dispuso de datos confiables y lo suficientemente amplios sobre las escuelas del Programa P900. Estos datos comprenden las calificaciones de los maestros, la tasa de rotación de éstos, la relación profesor/ alumno, las tasas de deserción y de repetición, la estructura y las instalaciones de las escuelas, el nivel de capacitación y experiencia de los directores y los ingresos y gastos de las instituciones escolares.
}

taron dos escuelas comparables, de buen desempeño y que habían egresado del Programa, a fin de lograr una visión más amplia.

La ubicación exacta de las escuelas en el mapa sólo se hizo una vez concluida la selección definitiva (véase el mapa 1). De esta manera se evitó tener en cuenta la conveniencia y facilidad de acceso en la elección de las escuelas. La visita a la escuela de Taltal entrañó un viaje de cuatro horas en autobús desde el aeropuerto más cercano (Antofagasta) y dos noches de

MAPA 1

\section{Chile : Ubicación de las escuelas visitadas para los estudios a nivel micro}

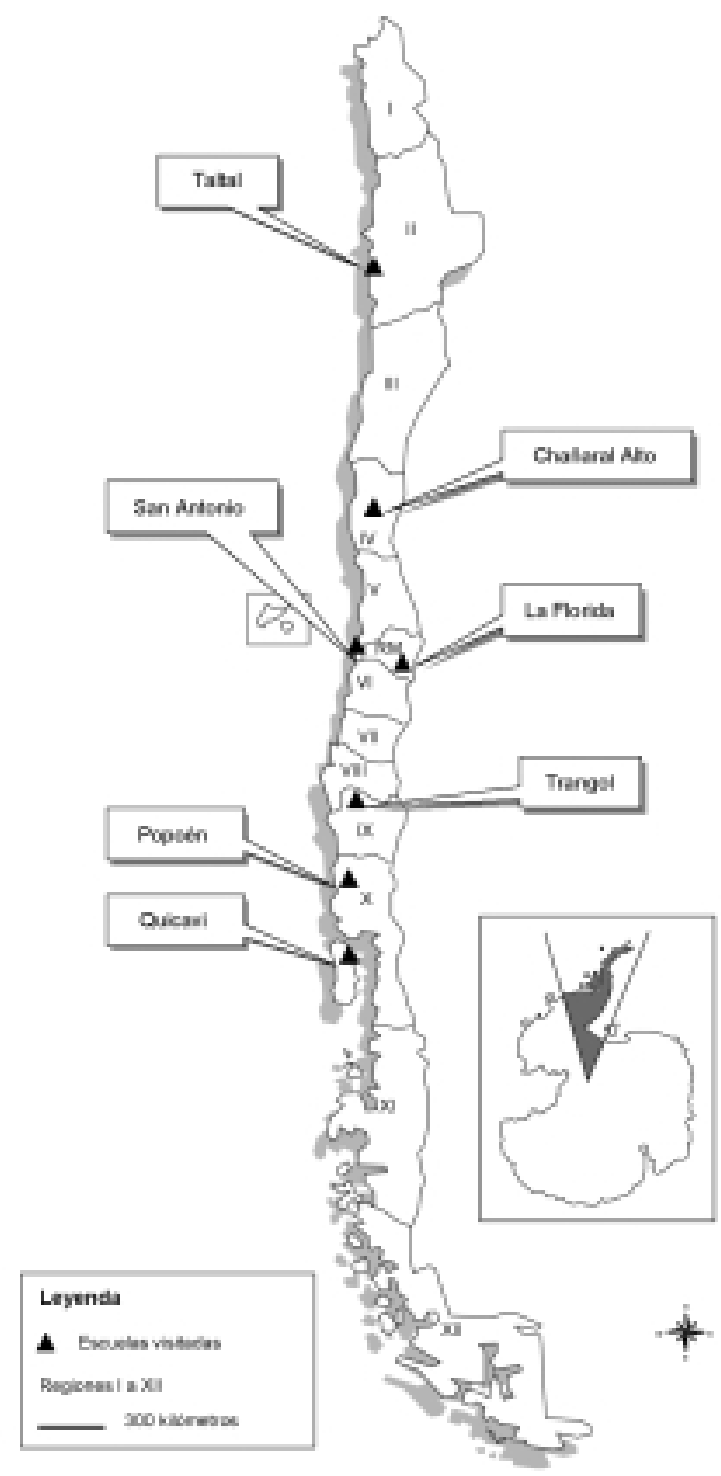

Fuente: Elaboración propia. 


\begin{tabular}{|c|c|c|c|c|c|c|c|}
\hline Región & Localidad & Municipal o & Urbana o & Matrícula & Nivel según & $\mathrm{N}^{\circ}$ de años & Puntaje del SIMCE de $4^{\circ}$ grado $^{b}$ \\
\hline & & $\begin{array}{l}\text { privada } \\
\text { subsidiada }\end{array}$ & rural & 1997 & $\begin{array}{l}\text { la JUNAEB } 1997 \\
\text { (quintiles) }^{\mathrm{c}}\end{array}$ & en el P900 & 1990 \\
\hline
\end{tabular}

Escuelas de bajo desempeño

\begin{tabular}{|c|c|c|c|c|c|c|c|c|c|c|}
\hline $\mathrm{X}$ & Popoén & Subsid. & Rural & 80 & 4 & 6 & 53 & 47 & 38 & 49 \\
\hline IX & Trangol & Mun. & Rural & 72 & 5 & 8 & 30 & 32 & 41 & 39 \\
\hline XII & La Florida & Subsid. & Urbana & 642 & 2 & 7 & 41 & 44 & 46 & 47 \\
\hline V & San Antonio & Mun. & Urbana & 518 & 3 & 8 & 46 & 56 & 56 & 57 \\
\hline IV & Chañaral Alto & Mun. & Rural & 681 & 4 & 7 & 55 & 62 & 67 & 57 \\
\hline II & Taltal & Mun. & Urbana & 1110 & 2 & 5 & 53 & 64 & 64 & 60 \\
\hline \multicolumn{11}{|c|}{$\begin{array}{l}\text { Escuelas de buen } \\
\text { desempeño }^{\mathrm{d}}\end{array}$} \\
\hline$X$ & Quicavi & Mun. & Rural & & 3 & 6 & 55 & $\ldots$ & 68 & 70 \\
\hline V & San Antonio & Mun. & Urbana & 1158 & 1 & 6 & 54 & 67 & 68 & $\ldots$ \\
\hline
\end{tabular}

a $\mathrm{P} 900$ = Programa de mejoramiento de la calidad de las escuelas de sectores pobres (o Programa de las 900 escuelas para sectores pobres).

b Promedio de los puntajes de matemáticas y castellano.

c Quintiles de 1 a 5 según el índice de vulnerabilidad utilizado por la Junta Nacional de Auxilio Escolar y Becas (JUNAEB).

1 = Vulnerabilidad mínima $(0-32)$

2 = Vulnerabilidad baja (33-44)

3 = Vulnerabilidad media (45-56)

$4=$ Vulnerabilidad elevada (57-66)

5 = Vulnerabilidad muy alta (67-100)

d En San Antonio se eligió como comparador una escuela de buen desempeño que acababa de egresar del P900, ubicada muy cerca de la escuela de bajo desempeño seleccionada para el estudio. También se informa sobre una visita a un internado rural, pobre pero de buen desempeño, ubicado en Quicavi, Chiloé. Esta escuela se seleccionó como comparador de las escuelas rurales de bajo desempeño, ubicadas en las regiones IX y $\mathrm{X}$ e incluidas en el estudio.

permanencia en la ciudad. Para llegar a otra de las escuelas, ubicada en Chañaral Alto, fue preciso viajar en automóvil durante una hora desde Ovalle que, a su vez, se encuentra a dos horas de automóvil del aeropuerto más cercano (La Serena). Las visitas a las escue- las de Popoén y Trangol significaron un viaje de más de cuatro días utilizando como punto de partida los aeropuertos de Osorno y Temuco, respectivamente. Se obtuvieron como resultado ocho estudios de casos de escuelas, inalterados y exhaustivos (cuadro 1). ${ }^{9}$

\section{IV}

\section{¿Qué nos enseñan las escuelas?}

¿Qué hace que una escuela sea buena? ¿Qué se necesita para que una comunidad pobre pueda tener una buena escuela? $\mathrm{O}$, dicho de otro modo, ¿qué impide que una escuela sea buena? Las entrevistas realizadas en las escuelas permitieron conocer muchos aspectos de la realidad y pusieron de manifiesto hechos bien conocidos por los padres, los educadores y los estudiantes. Las posibilidades de cambio no dependen de un factor único. La educación de los jóvenes es un proceso complejo y en la escuela se ponen en juego muchos factores, que son acumulativos: buenos docen- tes; un director de alto nivel; un currículo eficaz; suficientes fondos para llevar a cabo los programas; niños bien alimentados, motivados y dispuestos a aprender; la participación de los padres; instalaciones y aulas adecuadas; clases con pocos alumnos; escuelas ubicadas cerca de los hogares; una enseñanza creativa, y una población estable de alumnos y maestros.

\footnotetext{
${ }^{9}$ Véase una descripción completa de la historia de cada una de las escuelas en Carlson (2000).
} 
Estos factores se superponen y plantean dificultades más graves en las escuelas de comunidades pobres. Tener una buena escuela en un entorno pobre exige más esfuerzo y es un desafío permanente que se renueva año tras año. Estas escuelas fueron seleccionadas porque su desempeño, medido por los resultados de pruebas estandarizadas, era inadecuado. Pero en todas ellas intervenían factores que les eran peculiares y cada una nos podía enseñar cosas distintas. Si bien en este caso las lecciones son válidas más estrictamente para las escuelas de bajo desempeño en entornos difíciles, también tienen significado para los establecimientos escolares en general. Podemos observar que las escuelas de bajo desempeño no son todas igualmente "pobres" o "vulnerables", ya que pertenecen a cuatro de las cinco categorías de vulnerabilidad medidas mediante el algoritmo del programa nacional de alimentación escolar utilizado para asignar almuerzos escolares. La vulnerabilidad socioeconómica es sólo uno de los factores que determinan su desempeño.

Las reformas iniciadas por el gobierno central para mejorar la educación son inversiones a mediano y largo plazo. Deberán transcurrir no menos de cinco o diez años para que todas las escuelas puedan verlas funcionar con eficacia. Se necesitará cierto tiempo antes de que se hagan sentir los efectos de la reforma de los planes de estudios, de la capacitación de los docentes y de la educación de jornada completa. Entre tanto, es necesario aplicar medidas focalizadas para mejorar el funcionamiento de las escuelas en el marco de los parámetros existentes.

\section{1. ¿Qué nos enseñan las escuelas sobre el des- empeño de docentes y alumnos?}

Las visitas a las escuelas no tenían por objeto realizar una evaluación rigurosa de la enseñanza propiamente dicha impartida en las aulas. Para ello hubiera sido necesario llevar a cabo un estudio especializado y detenido, focalizado en ese tema solamente, y dedicarle más tiempo. En todas las escuelas se visitaron las aulas, especialmente las de $4^{\circ}$ grado, y se observaron algunas clases. En algunos casos el docente había dividido a los alumnos en grupos. Las entrevistas con los profesores, los directores y los estudiantes permitieron obtener mucha información. Había cierta retórica sobre la educación centrada en los niños, en parte como resultado de las actuales recomendaciones de política impartidas a los docentes que habían participado en los talleres de mejoramiento de la enseñanza organizados por el Ministerio de Educación.
El problema, por supuesto, era el de poner en práctica las normas. Efectivamente, un docente puede influir en los resultados, aun en una escuela pobre. En 1992 , por ejemplo, los niños de $4^{\circ}$ grado de la Escuela Hogar de Taltal obtuvieron calificaciones en matemáticas y castellano muy superiores a las de los años anteriores (62 y 65 sobre 100, respectivamente), que se atribuyen a tres docentes particularmente buenos. En 1996 las calificaciones cayeron en dos puntos en castellano y en siete puntos en matemáticas. Esto se debió, en buena medida, a que los docentes habían cambiado.

Hay una enorme diferencia entre el promedio de edad de los docentes de las escuelas municipales — que tienen un trabajo "vitalicio"- y los de las escuelas privadas subvencionadas, que pueden ser despedidos fácilmente. Fue notable observar cuán elevado era el promedio de edad de los docentes de muchas de las escuelas visitadas. Según el director de la escuela de Taltal esto era así porque no podía conseguir nuevos profesores dispuestos a venir a ese lugar tan apartado. Dos de los profesores a quienes pueden atribuirse los excelentes resultados obtenidos en 1992 y 1994 han jubilado y contratar nuevos profesores es una tarea difícil, si no imposible. Taltal es una ciudad de 12000 habitantes, ubicada en el desierto al sur de Antofagasta, la ciudad más cercana, a la que se llega tras cuatro horas de viaje en autobús. Como está muy aislada y hay que transportar la mayor parte de las mercancías en camión, el costo de la vida es elevado. Todos estos factores contribuyen a mantener alejados a los profesionales jóvenes. "Usted llama a concurso a Taltal y no va nadie. Prefieren las grandes ciudades", dijo Alfaro, ex supervisor del P900.

Si bien algunos docentes veteranos se resisten al cambio, un número igual le da la bienvenida y lo utiliza a su favor. Los docentes de $1^{\circ}$ a $4^{\circ}$ grado de Taltal desarrollaron un proyecto que obtuvo fondos del Ministerio de Educación para una sala audiovisual; como el proyecto fue elaborado por los propios profesores, éstos lo utilizan con más frecuencia y lo han integrado a sus planes de clase. Los maestros de Popoén atribuyen las destacadas calificaciones en ciencias al uso frecuente de videos educativos, mostrados en un videograbador y un televisor ganados mediante un Proyecto de Mejoramiento Educativo (PME). ${ }^{10}$

\footnotetext{
10 Los Proyectos de Mejoramiento Educativo son proyectos innovadores para mejorar la calidad de la enseñanza, que reciben un subsidio de tres años del Ministerio de Educación.
} 
La capacitación permanente de los docentes experimentados es tan importante como los cambios en los métodos de capacitación de los nuevos maestros. Sería muy ventajoso utilizar buenos videos sobre aulas "ideales" para demostrar a los docentes y a los estudiantes los métodos y las prácticas que podrían contribuir a mejorar los sistemas de enseñanza y de aprendizaje. Estos videos serían especialmente eficaces si mostraran ejemplos reales, tomados en escuelas pobres o que funcionan en entornos difíciles.

Sin embargo, la dificultad más grave, incluso para los profesores más innovadores, radica en el gran número de alumnos por aula y el hacinamiento. En la escuela Movilizadores Portuarios de San Antonio, que ha logrado resultados excelentes, el problema más serio es el número creciente de padres que desean que sus niños estudien allí. Los docentes temen que esto podría afectar el desempeño de los alumnos. Hay demasiados cursos con 45 estudiantes, lo que dificulta la realización de clases interactivas que, para los docentes, es la mejor manera de aprender. También es virtualmente imposible salvar la brecha entre los estudiantes que aprenden más lentamente y los más avanzados. Las diferencias en la calidad y cantidad de los materiales de enseñanza en las aulas, de los libros de texto y de los cuadernos de los estudiantes eran enormes y muy evidentes, aún en estas escuelas plagadas de dificultades. Algunas escuelas y aulas eran realmente deficientes. Tal es el caso de la escuela de Chañaral Alto, que ni siquiera se halla entre las escuelas más vulnerables. Era muy notable la mala calidad de los cuadernos de los alumnos y de su trabajo individual en ellos. En algunos casos, su escritura era casi ilegible.

\section{2 ¿Qué nos enseñan las escuelas sobre la falta de participación de los padres?}

En todas estas escuelas, que se esfuerzan por superar tantas dificultades, la falta de participación de los padres era un problema serio. Aunque esto no es nada nuevo, los ejemplos concretos proporcionados por las personas entrevistadas son, sin duda, aleccionadores, e ilustran la gravedad de esta situación en las familias pobres.

La clave para entender la contradicción aparente entre los proyectos innovadores en materia educativa y los bajos puntajes obtenidos por la escuela de Trangol en las pruebas nacionales del simCE está en los propios alumnos. Casi el $100 \%$ de los niños son mapuches de pura cepa, que prácticamente no hablan español cuando ingresan a la escuela. Sus padres los matriculan más por el desayuno y el almuerzo que reciben diariamente que por el alimento intelectual que puedan recibir en clase. Esto es comprensible teniendo en cuenta el mínimo nivel de educación de los propios padres. En promedio, los hombres apenas tienen cuatro años de educación escolar y la mitad de las mujeres son "analfabetas por desuso" de su capacidad de lectura y escritura. Estos padres rara vez se interesan en las actividades escolares de sus hijos y a veces ni siquiera saben en qué curso están. Hace poco se convocó a una reunión de apoderados con los docentes y sólo 10 de 68 se molestaron en asistir. "Nunca ha venido un apoderado a preguntar cómo le va a su hijo", dijo Mary Torres, que ha enseñado en Trangol durante nueve años y está a cargo de los niños de $1^{\circ}$ y $2^{\circ}$ grado. "No se refuerza en casa lo que se aprende en la escuela. Un día lo saben y al día siguiente se les olvida".

Con una escolaridad media de 3.5 años, los padres de los niños de Popoén se interesan poco y nada en las actividades escolares de sus hijos. "Los niños aquí tienen una enorme carencia de afecto y eso afecta su capacidad de aprender", dijo el director. La escuela compró un autobús para recoger a los alumnos internos todas las semanas y llevarlos de regreso a sus hogares los viernes, por lo que la asistencia ha mejorado considerablemente.

El grueso de los estudiantes que asisten a la Escuela Hogar de Taltal no recibe ayuda o refuerzo suficiente en su casa sobre lo que está aprendiendo en la escuela. Algunos de los varones mayores deben alternar entre el trabajo y las clases. Un día trabajan y el otro van a la escuela. "Hay mucho trabajo social" dijo la profesora del $8^{\circ}$ grado, Rosa Ovalle Fernández, quien ha enseñado en la Escuela Hogar durante 16 años.

Trifeña Tarita Chirino es una niña de $4^{\circ}$ grado que lee con la fluidez propia de sus nueve años, pese a ser una de 17 hermanos y hermanas que trabajan recolectando y vendiendo algas marinas. Su profesora dice que le encanta aprender y que a veces le golpea la puerta después del horario escolar para pedirle un lápiz o su ayuda con alguna pregunta. "Le hablo a su mamá y le digo que la ayude, pero parece que estoy hablando en otro idioma", dijo la profesora Patricia Jiménez Rojas. Las calificaciones de Trifeña, cuyo promedio es 4.4 sobre un máximo de 7, reflejan la falta de preocupación de sus padres. Sin embargo, en la misma clase, Cristián Astudillo Collao se enorgullece de su promedio de 6.2. Feliz y confiado, este niño de nueve años anuncia que cuando crezca será paleontólogo. Su padre trabaja en una planta termoeléctrica. 
Tras años de eludir las quejas de los profesores por la composición de las clases, el director de la Escuela-Hogar cambió el sistema para decidir la integración de cada clase. Cuando los padres llegan a inscribir a su hijo en el colegio tienen que seleccionar al docente que lo acompañará de $1^{\circ}$ a $4^{\circ}$ grados. Si la lista de estudiantes de una profesora particularmente buena se completa rápidamente, los apoderados tendrán que conformarse con un docente distinto. Los últimos en inscribir a sus hijos seguramente tendrán los peores profesores y condenarán a los niños a una enseñanza mediocre durante cuatro años consecutivos. Así, en última instancia, los niños cuyos padres no entienden bien el valor de la educación a menudo terminan siendo víctimas de la reticencia de la escuela para asumir la responsabilidad que le corresponde en la integración de las clases.

Este sistema injusto permite al director evitar las quejas y, teóricamente, motiva a los malos docentes a que mejoren. "Hacemos esto, precisamente, para que el profesor mejore su quehacer, porque no debería haber profesores mediocres", dijo Rojas. Desgraciadamente, admitió, hay docentes que no se inmutan si son los últimos en ser elegidos, de modo que en la práctica este incentivo no funciona. No obstante, si un niño tiene la suerte de tener un profesor excelente desde $1^{\circ}$ a $4^{\circ}$ grados, probablemente seguirá siendo un buen alumno de $5^{\circ}$ grado en adelante, cuando normalmente comienza a aplicarse el sistema de un profesor por materia.

Los cambios introducidos en los procedimientos disciplinarios de la escuela Unidad Divina, que es una escuela grande de barrio ubicada en el sector pobre de La Florida, un gran distrito de la capital del país, Santiago, desencadenaron conflictos con los padres, que tienden a ser agresivos y se ocupan muy poco de la educación de sus hijos. "Nuestro apoderado tiene una visión muy cómoda de la educación del niño. Espera que todo lo haga la escuela, desde enseñarle a ir al baño hasta lo más importante en contenidos", dijo el director. Esta escuela no tiene Centro de Padres, pues el que había se cerró. Ramón, un docente de $8^{\circ}$ grado, considera que la falta de ayuda de los padres es uno de los problemas más graves de la escuela. "No hay ningún compromiso de los padres; los niños se quedan con lo que hacen en el colegio".

La mayoría de los padres no participan en las actividades de la escuela San José de Calasanz, de San
Antonio. Muchas veces envían a sus hijos a trabajar en el mercado, a cuidar automóviles o a pedir limosna en la calle, en lugar de enviarlos a estudiar. Muchos niños llegan a la escuela sin sus materiales y los profesores tienen que dárselos. Un docente recordó a varios estudiantes cuyas madres nunca vinieron a retirar los libros de texto enviados por el Ministerio de Educación. "Se los entregué directamente a los niños; no podíamos seguir esperando a los padres", dijo.

Ubicada a sólo cinco minutos de marcha de la escuela San José de Calasanz, que tiene tantos problemas, la escuela básica 479, Movilizadores Portuarios de San Antonio, tiene tan buena reputación y atrae a tantos padres, que su único problema grave es no disponer de sitio suficiente para todos los alumnos. Esta escuela demuestra lo que puede lograrse cuando los administradores y los padres trabajan juntos y refleja la adhesión de padres que gozan de una situación de movilidad social ascendente y de un mayor nivel socioeconómico y educativo. En general, los apoderados de los niños de esta escuela han casi terminado la enseñanza media, aunque algunos tienen estudios universitarios. La vida familiar es estable y tres de cada cuatro hogares están formados por ambos progenitores y sus hijos.

El Centro de Padres trabaja activamente con la escuela y tiene una excelente relación con el personal, que valora sus esfuerzos. Se ha ocupado de recaudar fondos para mejorar los pisos, comprar libros para la biblioteca, financiar la construcción de una nueva multicancha, construir baños para el jardín de infancia y revestir con concreto la zona de juegos. Los padres también compraron una fotocopiadora y financiaron el personal de aseo que limpia las aulas.

A cambio de esto, son sumamente exigentes con el nivel de la enseñanza que imparten los docentes a los niños. Tienen sumo interés en los resultados de la escuela en las pruebas del SIMCE y muchos de ellos están dispuestos a ayudar, no sólo con dinero, sino dedicando su tiempo. Algunos trabajan como monitores en el taller y otros se ofrecen como voluntarios para los proyectos especiales. El año pasado trabajaron en el jardín de infancia en tres proyectos especiales centrados en la familia, el Mes del Mar y las Fiestas Patrias. Los temas que se ven en el aula reflejan el tema elegido y los padres contribuyen con anécdotas de la familia y colaboran con los niños y los monitores de la escuela para construir modelos y exhibiciones. 


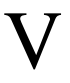

\section{Lecciones aprendidas}

Las entrevistas en las escuelas nos indican muy claramente que si bien los factores que afectan la calidad son acumulativos, cada uno de ellos puede tener profundas repercusiones positivas o negativas. Es fundamental identificar y comprender cuáles son estos factores, porque es posible modificarlos en el corto plazo. Reforzando la experiencia internacional, los informes de las escuelas nos indican que el factor individual más importante es tener un director de alto nivel que cuente con la autoridad suficiente para tomar decisiones. Nuestras visitas a las escuelas nos permitieron comprobar, sin lugar a dudas, que un plantel docente estable, capacitado y motivado es la fuerza vital de una buena escuela. Nos demostraron que un docente capacitado y dedicado puede lograr cambios mensurables en el desempeño de los alumnos. Por el contrario, si los maestros cambian con frecuencia y su nivel de capacitación e interés es bajo, el desempeño de los estudiantes decae inmediatamente.

Lo esencial es atraer y retener a docentes capacitados y a directores talentosos en las regiones pobres y remotas de Chile y en las escuelas difíciles de los vecindarios urbanos pobres. Los incentivos económicos no bastan para compensar la necesidad de la mayoría de la gente de vivir cerca de sus familiares y amigos. Los docentes jóvenes, que recién empiezan, están motivados y aún carecen de obligaciones familiares que los limiten. Tienen la posibilidad de trasladarse a las comunidades necesitadas. Pero tampoco se puede pretender que se queden indefinidamente. Un plazo razonable sería cinco años. A cambio, se les podría otorgar becas para realizar estudios avanzados u otros incentivos que compensen su contribución a las comunidades y estudiantes pobres. Además, estos incentivos serían una inversión en capital humano para el futuro de Chile.

Cabe preguntarse cómo podrían aplicarse estas lecciones en la práctica. Las autoridades de educación podrían instaurar auditorías de gestión de las escuelas, como las que se han llevado a cabo en este trabajo, a fin de determinar cuáles son los problemas y las prácticas esenciales que es preciso corregir. Si bien en la mayoría de los entornos no cabe esperar saltos cualitativos en materia de calidad, la detección y corrección de uno o más problemas graves puede mejorar significativamente el aprendizaje de los niños, como lo demuestran las visitas realizadas en este estudio. En Chañaral Alto hay que lograr que los profesores se queden; en Taltal es preciso negociar con el alcalde, cambiar al director de la escuela y mejorar las finanzas, y así sucesivamente. Pasemos revista ahora a lo aprendido de estas escuelas que atraviesan circunstancias difíciles y que reflejan la pugna por mejorar el desempeño de los alumnos.

\section{1. ¿Cómo lograr una educación de calidad? Un desafío que se renueva año tras año}

La educación en los vecindarios pobres plantea el desafío más importante a los funcionarios escolares y los alumnos. El uso de las tendencias de los puntajes obtenidos en la prueba del SIMCE para medir el éxito obtenido puede llevar a engaño, porque la hipótesis es que aquellos deberían seguir elevándose en la medida en que se preste especial atención a la escuela y se otorguen insumos también especiales. Si la enseñanza y la conducción de la escuela son buenas, los resultados de las pruebas deberían mejorar. Sin embargo, todos los años ingresa a la escuela una nueva cohorte de alumnos de jardín de infancia y de $1^{\text {er }}$ grado, que coloca nuevamente a las autoridades escolares frente a los mismos desafíos. Este aspecto es importante si se tiene en cuenta que hasta el $60 \%$ del desempeño escolar puede atribuirse al entorno social en que se desarrolla el niño, es decir, a factores extraescolares como la situación del hogar y el mayor o menor apoyo de los padres. "El ambiente educativo del hogar —el número de años de educación recibida por los adultos que integran el hogar- es el más importante y da cuenta de entre el $40 \%$ y el $50 \%$ de la incidencia de los factores socioeconómicos y familiares". ${ }^{11}$

Si las características de la población estudiantil se modifican considerablemente de un año a otro, estos cambios pueden afectar los resultados de la escuela. En la mayoría de los casos, es probable que la población estudiantil no cambie tanto, de modo que los docentes

\footnotetext{
${ }^{11}$ Véanse Banco Mundial (1995); Carlson, ed. (1999); CEPAL (1998) y Cohen, ed. (1998).
} 
enfrentan similares desafíos todos los años. Sin embargo, en cierto sentido, los resultados del desempeño medidos conforme al SIMCE pueden llevar a engaño. La prueba de desempeño bienal para $4^{\circ}$ grado es cada vez un fenómeno independiente y en cada prueba se evalúa un grupo distinto de alumnos de ese grado. En consecuencia, la tendencia de los puntajes obtenidos en las pruebas del SIMCE no es una medida demasiado precisa para determinar si la escuela sigue necesitando programas que compensen sus deficiencias, como el P900, o si está en condiciones de funcionar fuera de él. (Con posterioridad a la realización de estos informes se incorporaron al P900 otros factores cualitativos para determinar si la escuela está en condiciones de funcionar por su cuenta). Una escuela puede haber mejorado gracias a su participación en este Programa durante algunos años y esto se verá reflejado en los resultados de las pruebas del SIMCE. Pero cabe preguntarse si ese es el momento más adecuado para que la escuela egrese del P900, o para que permanezca en él y contribuya a que una nueva cohorte de alumnos de $1^{\text {er }}$ grado reciba una educación de mayor calidad. ¿Por qué habría de mantenerse el desempeño de una escuela si se reducen sus recursos?

\section{2 ¿Cómo lograr una educación de calidad? Ase- gurar que los progresos sean sostenibles}

Para que las escuelas puedan egresar del P900 es preciso que modifiquen radicalmente su funcionamiento. No sólo los alumnos deben aprender en él, sino también los administradores y los profesores. Es preciso encontrar maneras, en el marco del Programa, de proporcionar insumos sostenibles, de modo que la escuela pueda manejarse por su cuenta mejor que antes de ingresar a él. Sería necesario tomar examen a la escuela -y no solamente a los alumnos- para hacer un seguimiento de lo que ésta ha aprendido. Lo concreto es que el P900 sólo es un programa complementario, con recursos limitados. Es probable $-\mathrm{y}$ los relatos sobre las escuelas lo confirman- que los factores significativos para el mejoramiento sostenido de las escuelas sean de tipo general y no factores vinculados con un programa determinado. El P900 ha suministrado materiales excelentes para estimular a los profesores, los alumnos y los administradores escolares y ha formulado estrategias de difusión que son valiosas, pero quizás no sean sostenibles.

Los puntajes globales de las pruebas tampoco dan una idea acabada de la situación. En todas y cada una de las escuelas visitadas —aun las más pobres y atra- sadas- algunos niños sobresalían. Tenían una enorme sed de conocimientos y estaban absorbiendo todo lo que la escuela les podía ofrecer. En la escuela San José de Calasanz, de San Antonio, se pudo observar que un gran número de estudiantes tenía problemas de aprendizaje y necesitaba ayuda. La escuela estaba haciendo todo lo posible por satisfacer las necesidades de esos niños. Pero junto a estos, otros alumnos enfrentaban diversos desafíos, tanto en el aula como a través de programas especiales y actividades extracurriculares, como el periódico de la escuela. Ésta contaba con muchos patrocinadores en la comunidad, quienes donaban su dinero, su tiempo y sus capacidades para mejorarla.

\section{3. ¿Qué hace que una escuela sea buena? El di- rector}

Parecería que el factor más importante es el director de la escuela. Este puede provocar un viraje de 180 grados. Los cambios producidos por Dora Muñoz, en la escuela Unidad Divina del distrito de La Florida, de Santiago, llevaron tres años, pero están dando sus frutos como lo demuestran los resultados de la prueba del SIMCE de 1998 que rindieron los alumnos de $8^{\circ}$ grado. La directora ha logrado una multitud de cambios en una escuela difícil, pobre y hacinada, desde el reemplazo de profesores hasta el mejoramiento de la higiene del edificio. Otro ejemplo es Elsa Carrasco, directora de la escuela básica San José de Calasanz, de San Antonio, cuyo empuje empresarial, sumado a su entrega y creatividad, le ha permitido superar la adversidad, convirtiendo a la escuela en el centro de la comunidad y en un lugar de estímulo para los niños, cualquiera sea su capacidad. E Iván Rodríguez Mercado, director de la escuela de Trangol, al cabo de dos décadas sigue logrando que su escuela, minúscula y remota, sea una experiencia de aprendizaje bienvenida y cálida para sus paupérrimos alumnos.

En cambio, en la Escuela Hogar de Taltal, la falta de liderazgo es evidente y se debe tanto al autoritarismo del alcalde como al cansancio del director. La Escuela Básica Alejandro Chelén Rojas de Chañaral Alto espera a su nuevo director, mientras Claudina Rodríguez tiene las mejores intenciones y hace todo lo que está a su alcance para cumplir las funciones de directora interina, pero se ve muy limitada porque carece de las atribuciones necesarias. Lo que necesita la escuela de Chañaral Alto para cambiar de tónica es un líder dinámico y fuerte que logre modificar la situación del plantel docente. 
Un cambio importante que introdujo el innovador director de Quicavi fue el concepto de que todos los profesores deben participar en la administración de la escuela. "Cuando compartes las responsabilidades y la toma de decisiones, tienes un equipo más comprometido" dice. "Es la democracia". Quedó en el olvido el estilo de enseñanza utilizado anteriormente en la escuela, que hacía hincapié en la memorización. Se abrieron las puertas a la discusión, la explicación y el descubrimiento. El programa PME de la escuela financió la participación de los docentes en cursos especiales para capacitarse en el uso del equipo nuevo de la escuela y en temas como la comunicación oral.

Los bajos resultados de la escuela en las pruebas nacionales comenzaron a mejorar en forma sostenida. La tasa de repetición, que había llegado al $25 \%$, cayó al $1 \%$. Por primera vez ningún alumno de la escuela Aquelarre de Quicavi, de la isla de Chiloé, abandonó sus estudios. Pérez reconoce al plantel de siete profesores el mérito de haber transformado la escuela. "Una vez que superamos la resistencia a abandonar las viejas formas de enseñar, todos adoptaron el proyecto como un equipo y descubrimos que nos podemos divertir mientras trabajamos mejor", dice. Los profesores se turnan para vivir en la escuela durante una semana a fin de supervisar a los internos. Esto significa que los días laborables son más largos, pero cuando describen los aspectos positivos de la escuela tanto los maestros como los estudiantes hacen referencia al sentido comunitario.

Pedro Martínez, Jefe del Departamento Provincial del Ministerio de Educación de la X Región, considera que el ingrediente principal para lograr una buena escuela es el director. "El gran éxito de una escuela depende de la capacidad de liderazgo del director. Si hay un buen director, éste logrará atraer a buenos profesores que elaborarán buenos proyectos que a su vez recibirán buenos subsidios", concluye Martínez.

Es preciso crear incentivos para lograr que los líderes más dinámicos asuman la dirección de las escuelas, especialmente las difíciles. No hay mayores diferencias entre esto y la tarea de recuperar una empresa que está decayendo. ¿Por qué no buscar activamente administradores de escuelas con aptitudes empresariales, de gestión y de manejo de la gente y otorgarles la autoridad que necesitan para crear una buena escuela? Es evidente que la calidad de los alumnos que ingresan no va a cambiar significativamente hasta que no se solucionen los problemas de la desigualdad y la pobreza, y éstos son de largo alcance. Mientras tanto, el sistema escolar puede enfrentar el desafío especial que representan las escuelas difíciles asignándoles los mejores líderes.

\section{$4 . \quad$ La jomada completa}

Habría que recordar que las visitas a las escuelas se llevaron a cabo durante la puesta en práctica de muchas de las reformas escolares mencionadas, y si bien se prevé que éstas permitirán mejorar la calidad de la educación, el proceso llevará tiempo. Sin embargo, en su transcurso, puede tener efectos positivos o negativos. La transición de la media jornada a la jornada completa significa, en la práctica, que para aplicar la reforma muchas escuelas deberán duplicar -y en algunos casos triplicar- el espacio físico con que cuentan. Este no es sólo un asunto de financiamiento. En las escuelas pobres, como las incluidas en este estudio, el espacio físico disponible en la ubicación que muchas de ellas tienen actualmente es de por sí insuficiente. Tras muchos años de crecimiento sin cambios en su infraestructura, estas escuelas ya están terriblemente sobrepobladas. El problema logístico que representa dedicar el espacio disponible a un solo turno significa que, como mínimo, es preciso duplicar el número de aulas. En la mayor parte de las escuelas visitadas esto no es viable. Las municipalidades se están viendo obligadas a buscar terrenos alternativos. Además, los problemas logísticos inherentes a la implementación de este cambio tienen repercusiones muy variadas en otros insumos escolares, como los profesores, los gastos ordinarios y la construcción de nuevas instalaciones para las cuales no hay espacio suficiente en las viejas escuelas. Ahora se ha puesto en marcha un programa especial del Ministerio para ayudar a las escuelas a solucionar este problema.

\section{Responsabilidades y obligación de rendir cuentas}

La calidad de la educación en las escuelas subsidiadas depende casi exclusivamente de decisiones y fuentes de financiamiento externas originadas en tres ámbitos principales: el Ministerio de Educación, el Departamento Provincial y la Municipalidad o el administrador privado. El grueso del financiamiento proviene de las autoridades nacionales, con sede en Santiago, en forma de subsidios o de pagos por alumno. Las cifras se calculan teniendo en cuenta los registros de asistencia mensual y el dinero se envía a las municipalidades para su administración. La gestión de las escuelas está a cargo de las municipalidades que deben suministrar 
el financiamiento adicional necesario para el equipamiento y el funcionamiento. Los aspectos pedagógicos y curriculares están a cargo del Ministerio de Educación, en Santiago. Los departamentos provinciales supervisan la aplicación de los programas del Ministerio en las escuelas.

Es preciso asegurar una mayor coordinación y una más clara asignación de responsabilidades entre estos tres ámbitos. Por el momento, las escuelas se "califican" sólo sobre la base de los resultados de las pruebas del SIMCE. En gran medida, el desempeño de las escuelas, medido mediante estas pruebas, depende de la calidad de su personal, es decir, los docentes y los administradores. Sin embargo, las decisiones sobre el personal de la escuela no están en manos de ésta, sino de las autoridades municipales locales. Cabe preguntar entonces cómo se califica a la municipalidad. Es preciso mejorar de alguna manera la coordinación entre la escuela, la Municipalidad, el Ministerio y las autoridades provinciales e instituir algún sistema de contrapesos y salvaguardias.

\section{Elevada relación alumno/docente}

Según la legislación chilena, las escuelas pueden asignar hasta 45 alumnos por aula y recibir un subsidio por cada uno de ellos. No hay subsidios por los alumnos que superen los 45 por aula. De este modo, las escuelas tienen un incentivo económico importante para que el número de alumnos por aula se acerque todo lo posible a esa cifra. ¿Cómo puede hacer un docente para dirigir una clase de 45 alumnos e impartirles una educación de calidad? Ciertamente, la situación dista de ser óptima. A título comparativo cabe señalar que el número promedio de alumnos por clase en las escuelas privadas de todo el país es de 24 por docente, mientras que en las escuelas privadas subvencionadas es de 38 y en las escuelas municipales llega a $35 .{ }^{12}$ Este problema era especialmente marcado en las escuelas privadas pobres, es decir las escuelas que son de propiedad privada, pero que reciben subvención estatal por alumno. Un ejemplo que viene al caso es el de la escuela Unidad Divina. Como sus recursos son limitados, depende en gran medida de las subvenciones para sufragar sus gastos más importantes; especialmente para pagar a los docentes sueldos aceptables. Por ese motivo, los propios docentes, junto con la administración de la escuela, organizaron una campaña para in-

12 Véase Chile, Ministerio de Educación (1998). corporar más alumnos. Según su propietario, la escuela de Popoén opera mayormente en rojo y él tuvo que volver a ejercer la docencia para ahorrarse un sueldo.

¿Cómo puede cotejarse esta situación con la experiencia y los conocimientos internacionales? El tema del tamaño de los cursos ha sido muy debatido habida cuenta del elevado costo de las clases menos numerosas. Hay muchos puntos de vista sobre este tema y las indicaciones son muy distintas según el nivel de enseñanza de que se trate. En el pasado se ha tendido a evitar las clases reducidas, al menos en los países en desarrollo, porque no es eficaz en función de los costos. ${ }^{13}$ Sin embargo, este criterio general no tiene suficientemente en cuenta las diferencias entre los países en desarrollo, y si bien puede ser adecuado para los de muy bajos ingresos, no lo es necesariamente para otros, como Chile. Por otra parte, cabe preguntarse por qué es necesario aplicar un criterio absoluto con respecto al tamaño de las clases.

Hay muchas informaciones recientes sobre el costo y los efectos de reducir ese tamaño y aún queda mucho por aprender sobre este tema. ${ }^{14}$ Se ha comprobado que en el corto plazo se favorece significativamente el desempeño escolar. Experimentos realizados en los Estados Unidos demostraron que, para los estudiantes pertenecientes a las minorías, el beneficio era dos veces mayor que para los de raza blanca. Se comprobó que la mayor parte de los progresos se producían en el jardín de infancia y en $1^{\text {er }}$ grado. Los efectos de largo plazo son más difíciles de determinar, pues otros factores pueden dificultar la definición de los resultados. Por otra parte, es necesario aclarar el significado de clases numerosas o clases reducidas. La que en los Estados Unidos, donde se realizan muchas de estas investigaciones, se considera una clase pequeña (por ejemplo, menos de 20 alumnos por clase en comparación con más de 20 alumnos por clase), sería muy pequeña para los estándares chilenos. Como es de esperar, los resultados de las investigaciones recientes indican que el costo de oportunidad de la atención individual a los alumnos es mayor en las clases más numerosas, y que con un número menor de alumnos el docente puede dedicar menos tiempo a mantener la disciplina y más tiempo a la enseñanza. En una clase menos numerosa, el maestro puede dar más instrucción individual, generalmente en favor de los alumnos que no reciben apoyo de los padres en el hogar. Los más

\footnotetext{
13 Véase Lockheed y Vespoor (1991).

14 Véase Grissmer, 1999.
} 
beneficiados por la reducción del tamaño de la clase son los alumnos de bajos ingresos y los pertenecientes a las minorías.

En algunos países de Asia oriental, como Japón y la República de Corea, la reducción del tamaño de las clases no produce los mismos resultados que en los Estados Unidos. En el Tercer Estudio Internacional de Matemáticas y Ciencia (TIMss) se comprobó que en esos países, si bien el número de alumnos en las clases era elevado, el desempeño escolar también lo era. Sin embargo, los docentes de Japón enseñan a través de disertaciones y éstas son las mismas cualquiera sea el número de alumnos en la clase. En Chile la reforma educativa está dirigida a cambiar la enseñanza "frontal" por un enfoque "interactivo" que exige mayor atención individual.

La participación de los padres es fundamental para el éxito del aprendizaje, especialmente cuando el número de alumnos por clase es elevado. Aun cuando el curso tenga menos de 20 estudiantes, el tiempo que puede dedicar un docente a cada uno de ellos es limitado. Para los padres es más fácil dar tiempo a sus hijos. Sin embargo, los alumnos de las familias pobres no reciben apoyo de los padres y la escuela debe compensar esta deficiencia en la transición del hogar a la escuela, especialmente en los primeros años de la enseñanza. Se ha comprobado que en los primeros cuatro años de escuela se puede lograr una mejora significativa del desempeño en el corto plazo si se reduce el número de alumnos por clase.

\section{Hacinamiento en las aulas}

¿Cómo se puede impartir una enseñanza de calidad si los alumnos están amontonados en aulas demasiado pequeñas? En varias de las escuelas visitadas se comprobó que las salas estaban sobrepobladas; este problema era especialmente grave en la escuela Unidad Divina, ubicada en la comuna de La Florida, de Santiago. Las pequeñas aulas estaban atestadas con 40 o más niños, sentados tan cerca el uno del otro, que prácticamente estaban "hombro a hombro". El problema se veía agravado por la transición al sistema de jornada completa ya que algunos cursos funcionaban todo el día y desplazaban a los que, de otra manera, hubieran utilizado las aulas en el turno de la tarde. En la Escuela Hogar de Taltal, más de 40 niños estaban amontonados en aulas diseñadas para no más de 35 niños. Este hacinamiento se observó en todas las escuelas, salvo en las más pequeñas.

\section{Los docentes: rotación, capacitación y partici- pación}

La Escuela Básica Alejandro Chelén Rojas, de Chañaral Alto, es un ejemplo elocuente de la importancia de los profesores. Los alumnos tienen una enorme necesidad de sentir el compromiso de los docentes. Es inevitable que los niños duden de su valía cuando perciben la falta de compromiso de sus maestros, los ven escabullirse al terminar el día para emprender el regreso a la civilización de la ciudad más cercana, descubren que solicitan licencias por enfermedad con suma frecuencia o renuncian tan pronto como pueden. Sólo 13 de los 26 docentes de la escuela viven actualmente en Chañaral Alto. El resto va y viene todos los días. El puntaje de $4^{\circ}$ grado en las pruebas del SIMCE de 1996 cayó abruptamente porque esa cohorte de alumnos tuvo 12 profesores en un período de cuatro años. En cambio, los alumnos de $8^{\circ}$ grado tuvieron una docente excelente desde $1^{\circ}$ a $8^{\circ}$ y este hecho se reflejó en un aumento de 15 puntos en las clasificaciones de las pruebas del simce. Como resulta tan difícil encontrar docentes, 11 de los 26 carecen de título, entre ellos los siete profesores nuevos. En el lapso de un año la escuela ha tenido tres directores y el cargo ha quedado vacante nuevamente. Es indudable que esta situación es catastrófica y debe corregirse. Si la escuela no puede retener a los docentes ipor qué mantenerla en la ciudad? ¿Por qué no transferirla a la población de mayor tamaño más cercana y transportar a los niños en ómnibus? Vale la pena examinar la relación costo-beneficio y los efectos de un cambio de esta naturaleza.

El ejemplo de Chañaral Alto puede ser representativo de un problema subyacente y valdría la pena investigarlo más a fondo: la dificultad de encontrar buenos docentes para las escuelas rurales que están demasiado lejos como para trasladarse con facilidad, pero no lo suficiente como para que los maestros opten por vivir en la comunidad.

En la escuela Unidad Divina del distrito de La Florida, de Santiago, la directora consideraba que los integrantes de su equipo de docentes habían aprendido a trabajar muy bien juntos y estaba muy contenta de que la rotación de maestros hubiera disminuido. El hecho de que se tratara de una escuela privada posibilitó estos cambios. No ocurre lo mismo en las escuelas municipales, en las que el sindicato de los profesores y la legislación regulan estrictamente los contratos.

La mayoría de los 16 profesores de la Escuela Unidad Divina proviene de institutos profesionales. Casi todos están en la escuela todo el día, pues en sus 
contratos se estipula una semana de trabajo de 44 horas. El salario básico es bajo y la escuela comenzó a otorgar bonificaciones como incentivo a los profesores eficientes y eficaces. Los profesores valoran los esfuerzos de la directora y la facilidad con que aprueba los nuevos proyectos. Pero lo bajo de los salarios sigue siendo motivo de desaliento, particularmente cuando la realización de cursos de perfeccionamiento no se traduce en mejoras salariales. "No paga perfeccionarse", dijo Ramón, quien explicó que apenas contó con una pequeña ayuda del colegio para pagar su postítulo en orientación y que su mayor nivel de capacitación no se tradujo en un aumento de sueldo.

\section{Financiamiento de las escuelas: un problema de focalización inversa}

La escuela de Taltal resultó un hallazgo importante en lo que se refiere al funcionamiento concreto de la reforma educativa —o, en este caso, quizás habría que decir el no funcionamiento. Esta escuela se visitó, porque representaba el caso de una escuela muy grande, cuyo desempeño había mejorado, se había estancado y luego había decaído nuevamente, pese al P900 y las intervenciones de otros programas y proyectos. Según la hipótesis del Ministerio, era probable que las escuelas grandes tuvieran mayores dificultades para lograr progresos sostenidos. Por otra parte, la de Taltal no es una escuela muy pobre, como lo indica el índice de vulnerabilidad utilizado por la JUNAEB. En una escala de 1 a 5, el índice de la Escuela Hogar era de 2, lo que la ubica en una categoría de baja vulnerabilidad. Las características de la infraestructura física y de los niños observados durante la visita eran mejores que las de cualquiera de las otras cinco escuelas de bajo desempeño visitadas. El hallazgo al que hacemos referencia fue el alcalde local, quien tenía la autoridad para decidir cómo se distribuirían los fondos asignados a la municipalidad para financiar el funcionamiento de las escuelas. Este alcalde había decidido destinar fondos que correspondían a la escuela más grande y más pobre de la ciudad - la Escuela Hogar - a financiar el funcionamiento de las escuelas secundarias y las escuelas nocturnas, cuyo desempeño era deficiente en razón de una matrícula más reducida y una asistencia irregular. La Escuela Hogar tenía 1100 alumnos de nivel básico, cuya asistencia era obligatoria, y por lo tanto era la fuente de ingresos segura. Sin embargo, parte de estos ingresos se estaban transfiriendo para financiar el resto del sistema. Mientras tanto, entre otras carencias básicas, la escuela no tenía sillas suficientes en el comedor.

Este caso es un excelente ejemplo de la importancia que reviste analizar el desempeño a nivel micro además de hacerlo a nivel macro; de por qué es preciso analizar de primera mano el "cómo" y no limitarse a la información que llega a los estamentos superiores. Sin esta información pormenorizada lo lógico sería suponer que los subsidios otorgados sobre la base del número de alumnos se utilizan para lo que han sido otorgados y en las escuelas a las que han sido destinados. También puede ayudar a explicar por qué algunos funcionarios superiores del Ministerio consideraban que los "casos más difíciles" eran las escuelas muy grandes. Es probable que haya otros casos en que las municipalidades reasignan los fondos de las escuelas básicas más grandes para sufragar los gastos de las escuelas más pequeñas, las escuelas secundarias más caras y aquellas en las que la asistencia no es obligatoria - y por lo tanto es variable_- por lo que reciben subsidios más bajos. En este período de recesión y de crisis económica se está recortando aún más el presupuesto de las municipalidades y es muy posible que la práctica señalada se intensifique. Este es un caso muy claro de focalización inversa.

\section{Los programas especiales compiten con lo esencial}

Muchas escuelas están recibiendo insumos de programas especiales dirigidos a mejorar la calidad y la pertinencia de la educación. Además del Programa P900, la mayoría de las escuelas visitadas había ganado algún proyecto PME, es decir, un proyecto para mejorar la educación. En 1995 se otorgaron premios a 736 proyectos en las competencias de las escuelas básicas, en una amplia gama de áreas de aprendizaje: castellano, integración de temas, integración social, matemáticas, ciencias naturales, ciencias sociales, arte y educación física. Las escuelas básicas recibieron el equivalente de más de 4 millones de dólares, lo que representa un promedio de 6000 dólares - a valores actuales - por escuela para proyectos de dos a tres años de duración. La gran mayoría de estos proyectos se destinó al área de castellano $(60 \%)$. Un ejemplo característico es el proyecto de televisión en la Escuela Quicavi de Chiloé que tanto contribuyó a convertir el aprendizaje en algo vivo para los alumnos.

$\mathrm{Si}$ bien estos proyectos y programas aportan posibilidades enriquecedoras a los estudiantes, también exigen tiempo y atención de los maestros y los admi- 
nistradores. En más de una escuela se hizo referencia a esta situación. Por ejemplo, en la escuela de Chañaral Alto, que enfrenta las mayores dificultades para atraer y mantener a docentes y personal capacitados, si bien estaban muy orgullosos de su PME, también había preocupación por la falta de tiempo para la aplicación del P900 resultante de las exigencias del PME y de otros proyectos. Para ganar un Proyecto de Mejoramiento Educativo es preciso dedicar tiempo a la presentación escrita del proyecto y, cuando la escuela se lo adjudica, ocuparse de su ejecución y supervisión. Además, las escuelas reciben diversos insumos de programas especiales por los cuales deben competir. Esto no significa que no sean insumos útiles pero tienen un costo en materia de recursos.

Otro ejemplo es el innovador Proyecto Enlaces, cuyo objetivo es dar a los alumnos experiencia práctica en el uso de las computadoras. Uno de los requisitos es contar con una sala especial, con medidas de seguridad adecuadas. En primer lugar, es preciso capacitar a los docentes en el uso de las computadoras y luego capacitar y supervisar a los estudiantes. En la escuela Unidad Divina de La Florida se ha sacrificado la biblioteca para dedicarla al Proyecto Enlaces ya que no hay otra sala disponible. Daría la impresión de que este es un esfuerzo contradictorio por mejorar la calidad. Por un lado se aplica un proyecto innovador pero por el otro se afecta un elemento esencial para la enseñanza. La Escuela Hogar de Taltal tenía muchos oropeles, pero carecía de gran cantidad de elementos básicos. Las computadoras todavía estaban embaladas y una donación de equipo de laboratorio se exhibía con orgullo en la sala de multimedios mientras en las aulas los niños seguían, en su mayoría, con la misma rutina de siempre.

\section{1. "Tareas" para hacer en casa o ejercicios su- pervisados en la escuela}

Se pueden asignar tareas para realizar en casa, pero para muchos estudiantes pobres es difícil encontrar un lugar tranquilo para hacerlas. En muchas casas carecen de una habitación que ofrezca privacidad para hacer las tareas. En lugar de ello, es muy probable que los niños tengan que compartir la mesa del comedor con otros miembros de la familia que están mirando televisión, hablando o recibiendo a amigos. Los padres de bajo nivel educativo están menos dispuestos a ayudar a sus hijos con las tareas escolares y aún menos capacitados para hacerlo. Ramón, un docente de $8^{\circ}$ grado de la escuela Unidad Divina de La Florida, en
Santiago, considera que este es un problema grave: "en la casa dejan la mochila en un rincón, no la abren y, en la mayoría de los casos, ni siquiera tienen un lugar donde estudiar; y si tratan de hacerlo, deben estudiar en una mesa donde hay alguna radio o un televisor a todo volumen y un montón de chiquillos gritando". Este tipo de comentario se escuchó en la mayoría de las escuelas que tenían problemas de desempeño, mientras que en la escuela Movilizadores Portuarios de San Antonio, donde los resultados son satisfactorios, los padres son muy exigentes con los profesores y se interesan mucho por los resultados de la escuela en las pruebas del SIMCE, y colaboran como monitores de taller y en proyectos especiales. En lugar de quejarse por la situación precaria en los hogares, difícil de aceptar, la solución más constructiva podría ser brindar un entorno de trabajo "hogareño" en la escuela y realizar ejercicios supervisados en salas dedicadas a tal fin una vez finalizada la jornada escolar.

\section{2 ¿Qué hacer con los libros de texto?}

Los libros de texto son la expresión concreta del currículo y permiten a los estudiantes estudiar por su cuenta. Todos los años el gobierno llama a una licitación de libros de texto para los alumnos del sistema de educación subsidiada por el Estado, que representa el $93 \%$ de la matrícula total del país. La falta de libros de texto adecuados sigue siendo un obstáculo para lograr una educación de calidad y es preciso redoblar los esfuerzos para mejorarlos.

En muchos casos se escucharon quejas de los docentes sobre la escasez y la mala calidad de los libros de texto. Cuando el Ministerio de Educación envía los cuestionarios para que los profesores indiquen qué libros desean recibir, Rosa Ovalle Fernández, una maestra de la Escuela Hogar de Taltal, elige los libros cuidadosamente, pero en vano. "Elegimos siempre los mejores y siempre recibimos lo que esté disponible", se quejó. Una profesora de la escuela Movilizadores Portuarios, de San Antonio, dijo: "Me dio indignación comprobar que el libro de castellano de la Editorial Arrayán suministrado por el Ministerio, y que se vende en las librerías con un libro de ejercicios para los alumnos, nos llegue sin él. O sea que estamos en desventaja aun antes de empezar". Algunos docentes pasan revista todos los años a los nuevos textos escolares, compran los más útiles con su propio dinero, los fotocopian para los estudiantes y sólo les cobran las fotocopias.

Aunque la evaluación de los libros de texto no era un aspecto central del estudio, este tema se examinó 
más detenidamente. Si bien en 1990 muchos niños tenían que compartir los libros de texto, en los diez años siguientes el Ministerio de Educación ha triplicado el número de los enviados a las escuelas y ha indicado que en el año escolar que comienza en marzo del 2000 todos los estudiantes de la educación básica tendrían sus propios libros. También se están realizando esfuerzos por mejorar su calidad en consonancia con la reforma del currículo.

Dado el papel central que desempeñan los libros de texto en los resultados educativos, cabe preguntarse por qué no son mejores y qué hay que hacer para modificar esta situación. En un trabajo de investigación muy importante llevado a cabo por el Centro de Estudios Públicos (CEP), se realizó una evaluación exhaustiva de la calidad de los libros de texto utilizados en las escuelas chilenas subvencionadas por el gobierno. ${ }^{15}$ Para realizar el estudio del CEP se crearon dos comisiones: una para evaluar los textos de matemáticas y otra para los de castellano. El panel de expertos estaba integrado por personas de clase alta, media y baja, docentes universitarios, usuarios de los libros de

\section{VI}

\section{Conclusiones}

Muchas de las conclusiones extraídas de las visitas exhaustivas a las escuelas serán útiles para una proporción significativa de las escuelas básicas subsidiadas del país y contribuirán a mejorar la calidad y la equidad de la educación básica. Las entrevistas a las escuelas demuestran que si bien los factores de calidad son acumulativos, algunos de ellos generan cambios profundos. Es fundamental identificar y comprender estos factores, porque son ellos los que deberían modificarse en el corto plazo. Los relatos de las escuelas nos indican que lo que más incide en la calidad de ellas es tener un director de primera línea, que cuente matemáticas y castellano y directores de escuela. Todos coincidieron en que los libros de texto chilenos no alcanzan el nivel de los de España e Inglaterra -utilizados como elemento de comparación- y formularon conclusiones y propuestas sobre este tema.

La reforma de los libros de texto podría ser una manera relativamente rápida de producir cambios importantes en la calidad de la educación en lo que se refiere a los alumnos. Con buenos libros se puede mejorar inmediatamente el aprendizaje en el aula y el individual. La variedad de libros de texto disponibles en el mercado no es muy grande. El Ministerio está evaluando el proceso de licitación y los textos que se están usando, medida que ha sido muy bien acogida; pero subsiste el hecho grave de que el nivel de los libros de texto chilenos es inferior al internacional y no puede producirse un cambio real en el futuro cercano, a menos que se resuelva este problema crucial de calidad. Como se está realizando una reforma de los planes de estudio de la educación básica, es imprescindible iniciar cuanto antes una reforma de los libros de texto. con la autoridad suficiente para tomar determinadas medidas. También demuestran que un cuerpo docente estable, capacitado y motivado es la médula de una buena escuela y puede producir diferencias significativas en el desempeño de los alumnos. Por el contrario, si la rotación de los docentes es frecuente y su nivel de capacitación e interés es bajo, el desempeño de los estudiantes decae inmediatamente. El problema fundamental es atraer y retener a docentes capacitados y a directores talentosos en las regiones pobres y remotas de Chile y en las escuelas difíciles de los vecindarios pobres de las ciudades.

15 Véase Eyzaguirre y Fontaine, eds., (1997). 


\section{Bibliografía}

Angell, A. (1996): Improving the quality and equity of education in Chile: The programme 900 escuelas and the MECE-básica, A. Silva ed.: Implementing Policy Innovations in Latin America Politics, Economics and Techniques, Washington, D.C., Banco Interamericano de Desarrollo (BID).

Banco Mundial (1995): Priorities and strategies for education, Washington, D.C.

(1999): Educational Change in Latin America and the Caribbean, World Bank strategy paper, Washington, D.C., Latin America and the Caribbean Social and Human Development.

Carlson, B. (2000): Achieving Educational Quality: What Schools Teach Us, serie Desarrollo productivo, $\mathrm{N}^{\circ}$ 64, Santiago de Chile, Comisión Económica para América Latina y el Caribe (CEPAL), enero.

Carlson, B., ed. (1999): Social Dimensions of Economic Development and Productivity: Inequality and Social Performance, serie Desarrollo productivo, $N^{\circ} 56$, Santiago de Chile, CEPAL, agosto.

Carnoy, M. y P. McEwan (1997): Public investment on private schools: A reconstruction of educational improvements in Chile, Stanford, California, Stanford University.

CEPAl (1998): Panorama social de América Latina, 1997, Santiago de Chile, Departamento de Estadística.

Chile, Ministerio de Educación (1996): Compendio de información estadística 1996, Santiago de Chile, Departamento de Estadística.

(1998): Compendio de información estadística 1998, Santiago de Chile, Departamento de Estadística.

Cohen, E., ed. (1998): Educación, eficiencia y equidad: una difícil convivencia, Educación, eficiencia y equidad, Santiago de Chile, CEPAL/Organización de los Estados Americanos (OEA)/Ediciones SUR.

Cox, C. (1997): La reforma de la educación chilena: contexto, contenidos, implementación, Documentos PREAL, $\mathrm{N}^{\circ} 8$, Santiago de Chile, Programa de Promoción de la Reforma Educativa en América Latina y el Caribe (PREAL).

Espínola, V. (1996): Revisión de quince años de política educativa en Chile: ajustes en función de la equidad, Santiago de Chile, CEPAL.

Eyzaguirre, B. y L. Fontaine (1999): ¿Qué nos dice el SIMCE de $8^{\circ}$ Básico? Análisis y perspectivas, serie Documentos de trabajo, $N^{\circ} 294$, Santiago de Chile, Centro de Estudios Públicos (CEP).
Eyzaguirre, B. y L. Fontaine, eds. (1997): El futuro en riesgo: nuestros textos escolares, 1997, Santiago de Chile, CEP.

Gajardo, M. (2000): Reformas educativas en América Latina. Balance de una década, Documento PREAL, $\mathrm{N}^{\circ} 15$, Santiago de Chile, PREAL, enero.

García-Huidobro, J. (1999): La reforma educacional chilena, Santiago de Chile, Editorial Popular.

García-Huidobro, J. y C. Jara (1994): El programa de las 900 escuelas, M. Gajardo, ed., Cooperación internacional y desarrollo de la educación, Santiago de Chile, Ministerio de Planificación y Cooperación, AGCI/ASDI/CIDE.

Grissmer, D. (1999): Seminar on Class Size Effects: Assessing the Evidence, its Policy Implications, and Future Research Agen$d a$, Washington, D.C., RAND Corporation, septiembre.

JUNAEB (Junta Nacional de Auxilio Escolar y Becas) (1998): JUNAEB, Red nacional de apoyo al estudiante, programas 98.99, Santiago de Chile.

Lockheed, M. y A. Vespoor (1991): Improving Primary Education in Developing Countries, Washington, D.C., Banco Mundial.

Martínez, R. (1996): La prueba SIMCE y la medición de la calidad de la educación, Educación, eficiencia y equidad, Santiago de Chile, CEPAL/OEA/Ediciones SUR.

Mizala, A. y P. Romaguera (1998): Desempeño escolar y elección de colegios: la experiencia chilena, Documentos de trabajo, serie Economía, $\mathrm{N}^{\circ} 36$, Santiago de Chile, Universidad de Chile, Departamento de Ingeniería Industrial, Centro de Economía Aplicada (CEA).

Olivares, J. (1996): Sistema de medición de la calidad de la educación en Chile: SIMCE, algunos problemas de medición, Revista iberoamericana de educación, $\mathrm{N}^{\circ} 10$, Madrid, Organización de Estados Iberoamericanos para la Educación, la Ciencia y la Cultura (OEI).

PREAL (Programa de Promoción de la Reforma Educativa en América Latina y el Caribe) (1998): El futuro está en riesgo, Washington, D.C., Diálogo Interamericano, abril.

Rojas, C. y J. M. Esquivel (1998): Los sistemas de medición del logro académico en Latinoamérica, LCSHD paper series, $\mathrm{N}^{\circ}$ 25, Washington, D.C., Banco Mundial, Latin American and Caribbean Regional Office, octubre.

Schiefelbein, E. y P. Schiefelbein (1999): Repetition and quality of education in Chile; L. Randall y J. Anderson, eds., Schooling for Success, Sharpe, Armonk, Nueva York.

Undurraga, C. (1998): Reforma educacional en Chile: perspectiva de cinco ministros, Washington, D.C. BID. 